\title{
Importance of logistics services attributes influencing customer satisfaction
}

\author{
Gajewska Teresa \\ Faculty of Mechanics \\ Cracow University of Technology \\ Cracow, Poland \\ teresa.gajewska@mech.pk.edu.pl
}

\author{
Grigoroudis Evangelos \\ School of Production Engineering \& Management \\ Technical University of Crete \\ Chania, Greece \\ vangelis@ergasya.tuc.gr
}

\begin{abstract}
An attempt to assess customer satisfaction with the service quality is a common research topic pursued by many scholars. By analysing the existing research in the area of logistics services evaluation, including refrigerated transport, it should be noted that the issues concerned are presented in a selective manner.
\end{abstract}

The aim of this paper is to present the results of conducted surveys regarding the importance of the logistics services attributes influencing customer satisfaction in the field of road refrigerated transport. In order to respect the qualitative nature of collected information, a ordered weighted averaging technique (OWA) was applied. In turn, the rationale of the RR approach can also be applied in order to estimate the performance of the logistics service attributes as evaluated by the customers. The findings obtained from the interviews regarding the expectations and the evaluation of the quality level were used to perform analyses based on the so-called fifth vulnerability, developed by the Parasuraman team and included in the SERVQUAL method.

The research concerned an analysis of the key criteria for the evaluation of the quality of logistics services in the examined area.

The research was based on a questionnaire designed for purchasers of logistics services. The respondents were companies using refrigerated transport.

Key words-logistics services; customer satisfaction; refrigerated transport; ordered weighted averaging (OWA); Servqual method; RR approach

\section{INTRODUCTION}

The research was done in 2012 and was quantitative in nature. It was intended to assess the importance of the logistics services attributes influencing customer satisfaction with the quality of logistics services based on a case study comprising 5 companies which specialized in domestic and international road transport and domestic specialist transport of frozen products, and 25 customers using their services.

The transport of cooled produce was one of the first major applications of mechanical refrigeration. Refrigerated transport is necessary for maintaining the quality and prolonging the shelf-life of fresh, frozen and perishable products during transportation [23]. Logistics developments have enabled worldwide distribution of food under temperature-controlled conditions. The temperature of the commodity must be maintained within specified limits [17].

Logistics services can be evaluated first of all by measurement of customer satisfaction. Most researchers, such as Chen, Chang \& Lai (2009), Huang \& Huang (2012), Jaiswal (2008), Jayawardhena (2010), and Juga, Juntunen \& Grant (2010) emphasize in their works the very important role of the client in the sector of logistics services $[9,16,18,19,20]$. Using the gap model developed by the Parasuraman team, Chen, Chang and Lai (2009) analysed customer satisfaction with the quality of service from the viewpoint of both the service providers and their customers. In turn, in their research, Huang \& Huang (2012) measured the logistic capacity of service providers $[9,16]$. The logistic capacity was concerned with particular services, innovation and flexibility. The aim of the research done by authors such as Jaiswal (2008), Jayawardhena (2010), and Juga et al. (2010) was to assess the level of customer satisfaction and measure the quality of the services provided [18,19,20].

Customer satisfaction is often regarded as an indicator of the appreciation of the service provided. It is a confirmation or relates to confirmation of customer expectation $[9,15]$. Customer satisfaction measurement is one of the most important issues concerning business organizations of all types, which is justified by the customer-orientation philosophy and the main principles of continuous improvement of modern enterprises [14]. The concept of customer satisfaction can be defined in different ways in literature. Kotler and Andreasen define customer satisfaction as "the state felt by a person who has experienced a performance (or outcome) that has fulfilled his or her expectations" [21,28]. In order to assess customer satisfaction, the perceived service needs to be measured against the customer expectations of what was to be delivered. Then, the subjective feelings accompanying the use of the service which is offered are the basis for effective and reliable assessment and give a picture of the service concerned. Satisfaction measurement provides information on the organization and effective satisfaction of customer needs.

The relevant literature on this subject and the empirical studies confirmed the importance of the research problem, which is the ability to determine customer satisfaction with the 
quality of logistics services based on the example of refrigerated transport.

\section{DESCRIPTION OF THE RESEARCH METHOD}

The aim of the paper is to find out about and evaluate the expectations of purchasers regarding the quality of logistics services in the field of road refrigerated transport. The analysis comprised 10 attributes of logistics services influencing customer satisfaction.

The subjects of the research were both undertakings which provided logistics services in the field of road refrigerated transport, as well as their customers. The logistics providers were enterprises which specialize in the field of domestic road specialized transport, domestic and international road specialized transport, domestic and international road transport, domestic specialized transport and distribution in frozen products area. The purchasers of logistics services were manufacturers and distributors of food products, hypermarkets and specialist groceries.

The results obtained from the interviews regarding the expectations and evaluation of the quality level were used to perform analyses based on the so-called fifth vulnerability, developed by the Parasuraman team and included in the SERVQUAL method [6,13].

SERVQUAL is founded on the view that the customer's evaluation of service quality is paramount. This assessment is conceptualized as a gap between what the customer expects by way of service quality from a class of service providers, and their evaluations of the performance of a particular service provider [7].

The American school has predominantly used the SERVQUAL scale to measure and dimension service quality. This multi-item scale evaluates five quality dimensions from a global perspective [24]:

Reliability;

Reactivity;

Guarantee/safety;

Empathy; and

Tangible elements.

In order to estimate the importance of the logistics service attributes influencing customer satisfaction a ordered weighted averaging technique (OWA) and RR approach were used. Ordered Weighted averaging (OWA) operators can produce appropriate weights corresponding to each rank position by solving a well-designed mathematical program. Then the problem is that, even if the weights are generated to satisfy the rank order, they are just estimate of, as is well known, infinitely many candidate weights that satisfy the relation [1].

\section{QUESTIONNAIRE RESULTS}

The research was done in 2012 and was quantitative in its nature. The empirical study was begun with analyses of the qualitative data obtained from the interviews with 25 customers concerning the importance of 10 attributes of the logistics service influencing the customer satisfaction with the quality of the service and evaluations of these attributes [11]. The results were analysed in three dimensions recommended by Kozerska (2010), namely [22]:

a) expectations - to identify the quality criteria most important for customers,

b) assessments - to identify the highest valued characteristics - whatever the level of expectations,

c) the difference between the expectations and the evaluations - to identify the quality criteria which are most similar to expectations and the ones which are the weakest links in the service offering and to identify gaps.

\section{A. Results of Servqual method}

The results of the interviews with logistics service purchasers concerning the importance of the attributes of logistics services for service quality are presented in Fig. 1. For the analysis ten quality features from a total of thirteen logistic services features influencing customer satisfaction were selected, as proposed by the Logistics Operator of the Year. These features are the most widespread and they are considered in numerous conducted research efforts [25].

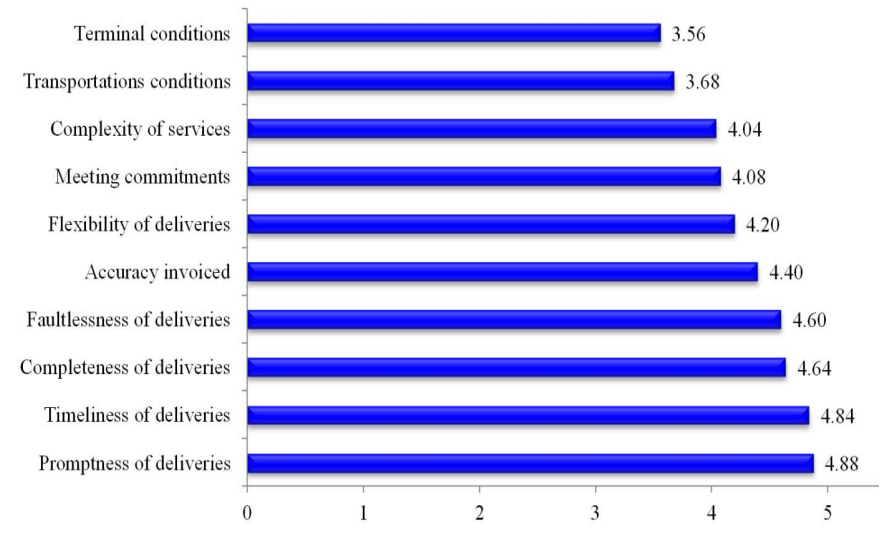

Fig. 1. Importance of the attributes of logistics services influencing customer satisfaction with the service quality (in points)

The averaged results were the basis for prioritizing the attributes of logistics services influencing customer satisfaction with the service quality (in points). It was concluded that according to customers' expectations, the most important attributes were: promptness of deliveries (4.88 pt.) and timeliness of deliveries (4.84 pt.), followed by completeness of deliveries (4.64 pt.) whilst the least important were: transportation conditions (3.68 pt.) and terminal conditions (3.56 pt.).

In turn, the results relating to the evaluation of attributes of logistics services which influence customer satisfaction with the service quality in the opinion of logistics service purchasers are shown in Fig. 2. 


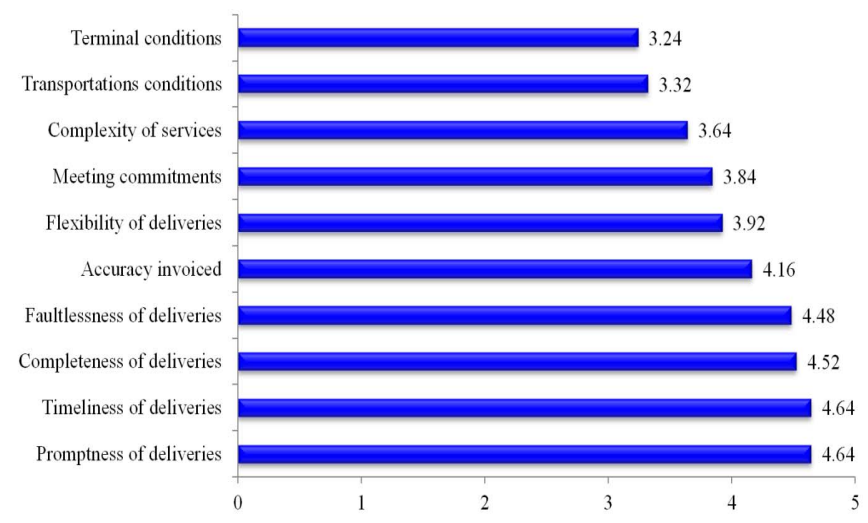

Fig. 2. Evaluation of the features of logistic services in the opinion of logistics service purchasers (in points)

It was concluded that in the opinion of customers using logistics services in the field of refrigerated transport, timeliness and promptness of deliveries (4.64 pt.) were the highest in their evaluations; these were followed by completeness (4.52 pt.) as well as faultlessness of deliveries (4.48 pt.). The respondents valued transportation conditions (3.32 pt.) and terminal conditions (3.24 pt.) the lowest.

For many customers, the promptness and timeliness of deliveries are closely interrelated, and even considered to be integrated. This was confirmed by very similar average figures concerning their importance. Timeliness of deliveries, meaning delivery exactly on time, indicates, at the same time, the acceptable speed of delivery. Similarly, the promptness of deliveries measured as the time which elapsed between the time the need was identified in an order and transferred to the supplier and the moment the delivery was effected (i.e., time of delivery) is very often linked to the timeliness of deliveries. A diagnostic measure of the timeliness of deliveries is the number and the percentage of consignments that are not supplied on time. However, there are no diagnostic measures of the speed of deliveries.

Similar average figures for the importance of the completeness and the faultlessness of deliveries also demonstrate a relation between these two attributes. However, according to the representatives of customers, they should be considered separately. A diagnostic measure of the completeness of deliveries is the amount and the percentage of incomplete deliveries, and a measure of their correctness is the number and the percentage of damaged consignments.

The lowest figures of the average evaluations of the importance refer to the transportation condition and the condition of the terminal (items 9 and 10, in order of priority set by service providers) confirm, on the other hand, their moderate effect on the overall evaluation by customers of their satisfaction with the quality of service, which is demonstrated by the correlation coefficient $r<0.5$. Correlation coefficient is a measure that determines the degree relation between evaluation of satisfaction from logistics services quality in refrigerated transport area on evaluation of an importance of a attributes of logistic service influencing customer satisfaction [12].
The compiled figures can be the basis for calculating the difference between customer expectations and their evaluations of the logistic services attributes affecting customer satisfaction. The results are provided in Fig. 3.

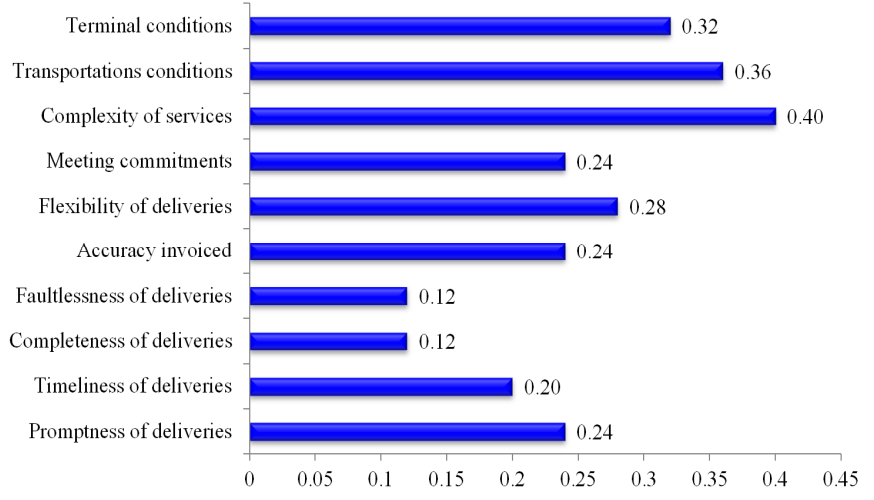

Fig. 3. Difference between the expectations and evaluations of customers concerning the importance of attributes of logistics services (in points)

The analysis of the results obtained which concern the difference between the expectations and the evaluations of logistics services and the results of tests carried out by Kozerska (2010), indicates a certain analogy with regard to the same characteristics [22]. The results showed that the differences between the expectations and the evaluations of customers regarding the logistics services attributes are quite low. The most important characteristics are also those with the highest evaluations. It should be noted that results conducted analysis is no service gap.

The lowest figure for the so-called fifth vulnerability obtained for the completeness and the faultlessness of deliveries points to the provision of services at such a level that expectations are met and customer satisfaction is high. The attribute which follows is the timeliness of supplies, with a slightly higher figure for the difference between the expectations and the evaluation of the service which is an indication of the customers' awareness of their expectations and the considerable importance they attach to the provision of high-quality service. The highest fifth vulnerability figures were noted for the complexity of services, transportation condition and the condition of the terminal. The complexity of services - the attribute ranked eighth out of ten in the hierarchy of importance and the level of its evaluations - does not offer adequate satisfaction with the service purchased. Remarks evidencing such a big discrepancy between the expectations and the service offering were repeatedly made during the interviews with customers. Their expectations were related to the purchase of extended service offerings which would include, in addition to refrigerated transport, processing of the orders they placed, inspection of goods, packaging or surveying the demand and sales forecasts. The reason for such a situation is that service providers pay less attention to such attributes than their customers. In the case of the transportation condition and the condition of the terminal, the least important service attributes and attributes which were ranked the lowest (ninth and tenth) as regards the fifth vulnerability, are slightly lower, but still high in comparison with the respective figures for the completeness and faultlessness of deliveries. 
Even though service purchasers do not attach as much importance to these characteristics as is the case of other features significantly affecting customer satisfaction with the service quality, they are aware of irregularities concerning means of transportation and terminals. The customer needs regarding proper technical condition of terminals and due preparation of the means of transport were also noted by other authors such as Brdulak (2008, 2009) and Dyczkowska (2011) $[4,5,10]$. Analyses of case studies demonstrated significant deficiencies as regards the observance of legal regulations on food transport. Even if the customer's satisfaction with the quality of services is high, because of high evaluations of material characteristics affecting that level, measures to improve service quality should apply to transport infrastructure too.

\section{B. Ordered Weighted Averaging (OWA) method and RR approach results}

Ordered Weighted Averaging (OWA) is an advanced set of methods in decision-making analysis that can provide a whole spectrum of alternative aggregation techniques. OWA operators are very popular in multiple criteria decision analysis (MCDA) since available information has usually the form of ordinal data, while they are able to take into account the decision-maker's (DM's) preferences [1,2].

The main advantage of the OWA operators is that they respect the qualitative (ordinal) form of preference data and, at the same time, they are able to model the different DM's preferences.

In the presented study, OWA operators are used in order to estimate the importance of logistics service attributes. As noted in the previous section, the importance of 10 quality attributes were evaluated by a total of 25 logistics service customers using a 5point ordinal scale. This justifies the applicability of alternative OWA operators.

One of the most widely-used OWA operator refers to the rank-reciprocal (RR) approach, where the estimation of weights are based on the following formula:

$$
w_{i j}=\frac{1 / r_{i j}}{\sum_{k=1}^{n}\left(1 / r_{k j}\right)}
$$

where $w_{i j}$ is the weight of the $\mathrm{j}$-th customer for the $\mathrm{i}$-th attribute, $n$ is the number of attributes, and $r_{i j}$ is the importance rank of the $\mathrm{j}$-th customer for the $\mathrm{i}$-th attribute.

Additional OWA operators, can be also applied in the examined dataset, including the rank-sum, the rank additive, the rank-centroid, the rank-factorial and the rank rank-power approaches. However, the attitudinal character of the RR approach is rather robust and is not heavily influenced by the number of attributes [1]. An analytical presentation and discussion of the alternative OWA operators used to evaluate rank-based weights, including their main advantages and limitations is given by Barron and Barret (1996), Roberts and Goodwin (2003), Ahn (2011), and Ahn and Choi (2012) [3,26, $2,1]$.
Fig. 4 presents the average importance of the logistics services attributes, as estimated by the aforementioned OWA operator for the total set of 25 customers. As it can be easily seen, the results are in general consistent with those presented in Fig. 1. The most important attributes that influence customer satisfaction with the quality of logistics services are the promptness and the timeliness of deliveries with weights $13.9 \%$ and $13.4 \%$, respectively. A relative high importance also appear for the quality attributes of completeness of deliveries (11.8\%) and faultiness of deliveries (11.5\%), while the least important logistics service attributes concern the terminal conditions $(6.4 \%)$ and the transportation conditions $(6.7 \%)$.

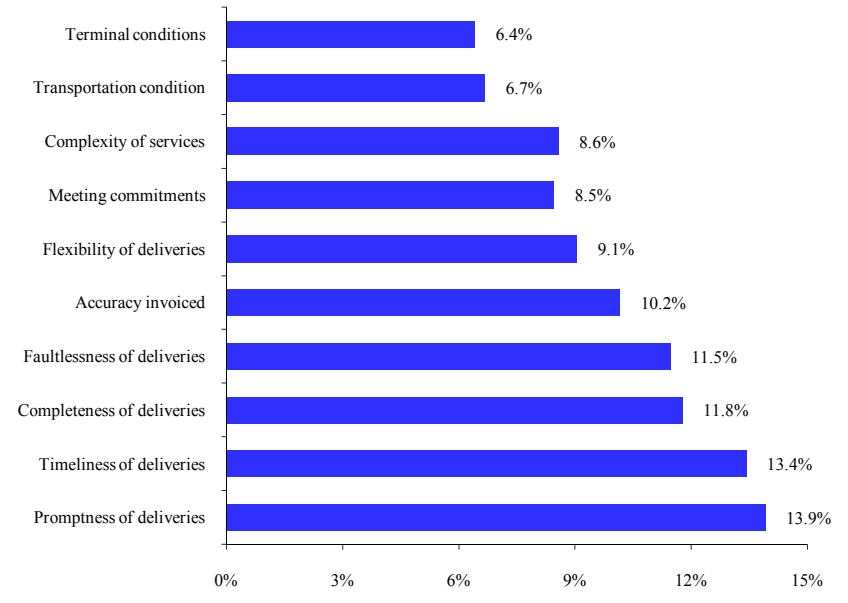

Fig. 4. Importance of the logistics services attributes influencing customer satisfaction by OWA operator (in \%)

It should be noted that the results provided by the OWA operator are normalized in $[0,1]$, and the sum of the estimated weights equals 1 . Thus, these results should be considered as the relative importance of the logistics services attributes.

The rationale of the RR approach can also be applied in order to estimate the performance of the logistics service attributes as evaluated by the customers. In this case it is not necessary to have normalized results, i.e., the sum of aggregated values should not equal 1. In particular, the estimations of the service quality evaluations are given by the following formula:

$$
e_{i j}=\frac{1}{\rho_{i j}}
$$

where $e_{i j}$ is the evaluation of the $\mathrm{j}$-th customer for the $\mathrm{i}$-th attribute, $n$ is the number of attributes, and $\rho_{i j}$ is the performance rank of the $\mathrm{j}$-th customer for the $\mathrm{i}$-th attribute.

It should be noted that the results provided by the previous formula are normalized in $[1 / n, 1]$. Thus, these results depend not only on the performance ranks given by customers $\left(\rho_{i j}\right)$, but on the number of attributes as well.

Using the aforementioned formula, the average evaluations of the logistics services attributes for the total set of 25 
customers are presented in Fig. 5. The most highly evaluated attributes refer to the promptness and the timeliness of deliveries, with an average evaluation of 0.82 . Also, based on customer expectations, the performance of the attributes referring to the completeness and faultiness of deliveries is also high, having an average evaluation of 0.77 and 0.74 , respectively. On the other hand, the level of fulfillment for the quality attributes of terminal and transportation conditions is relatively low, since they appear to have the lowest evaluation scores ( 0.40 and 0.38 , respectively).

These results are in general consistent with the findings of Fig. 2. However, it should be noted that the RR approach may discriminate better the performance of the examined quality attributes. This is somehow expected, given the non-linear nature of the applied formula.

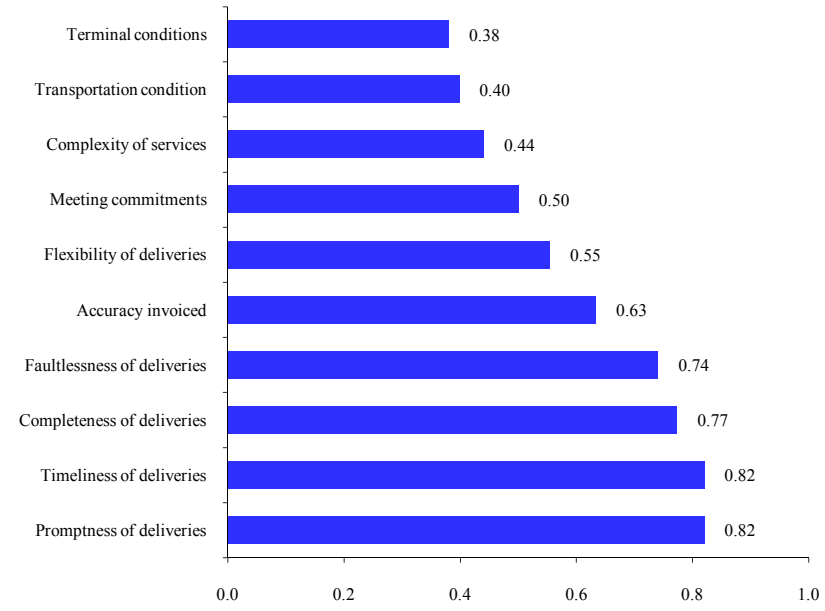

Fig. 5. Evaluations of the logistics services attributes influencing customer satisfaction by RR approach (in $[0,1]$ )

In order to perform a gap analysis between the estimated importance and the evaluation of the quality attributes, it is not possible to adopt the approach presented in section IIIA, since the figures estimated by the RR approach are not fully compatible (the sum of weights equals 1 , while this is not valid for the evaluations). For this reason, a performance-importance diagram may be developed, which is basically a scatterplot with weights as the horizontal axis and evaluations as the vertical axis. According to Grigoroudis and Siskos (2010) these diagrams indicate the strong and weak points of customer satisfaction and define the required improvement efforts [14]. They are also mentioned as decision or strategic maps and they are similar to SWOT analysis. In practice, such diagrams are able to present the gap in service quality offered to customers, i.e., the difference between what customer want (weights) and what customers get (evaluations).

Fig. 6 presents the gap analysis between the importance and the evaluations estimated by the RR approach. As it can observed, in general, the ten quality attributes are located in the diagonal of the diagram (i.e., the $x=y$ line of the scatterplot). This implies that there is no gap in the examined logistics service attributes, since the most important attributes are those having the highest evaluations.
This finding is consistent with the calculated differences of Fig. 3 which show that the differences between customer expectations and evaluations are relatively low regarding the quality of the examined logistics services attributes. It can be observed that the highest difference in Fig. 3, which refer to the complexity of services, is also the quality attribute is Fig. 6 further way from the diagonal of the gap analysis diagram.

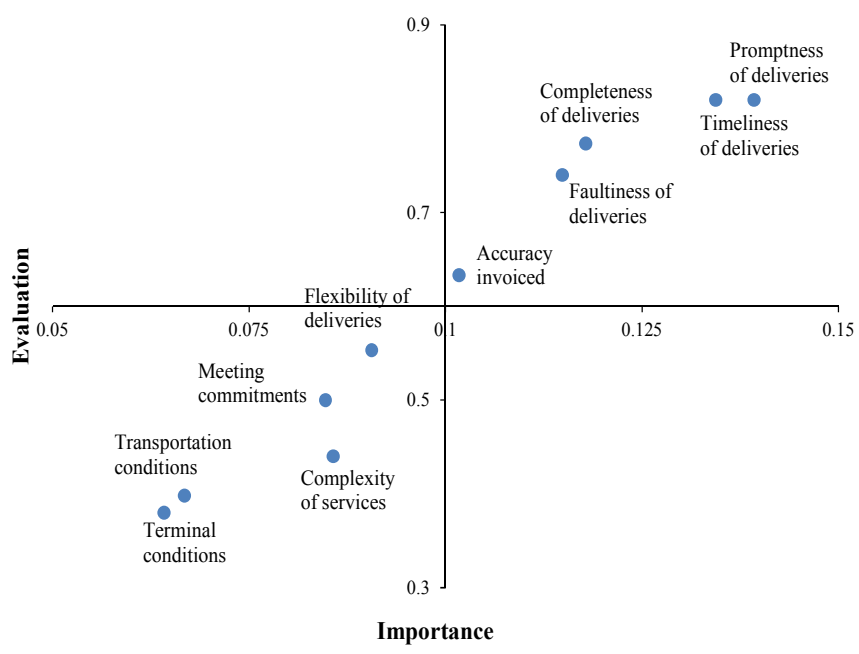

Fig. 6. Gap analysis between the expectations and the evaluation of the logistics services attributes influencing customer satisfaction by RR approach

\section{CONCLUSIONS}

This paper proposes results of conducted surveys regarding the importance of the logistics services attributes influencing customer satisfaction in the field of road refrigerated transport. Logistics services are the backbone of most logistics companies, and hence the high quality of services that they provide is important for getting competitive advantage [8]. The quality of logistics services is a key objective seen by the customer [27].

The results of the analysis with using Servqual method showed that the differences between the expectations and the evaluations of customers regarding the logistics services attributes are quite low. The most important characteristics are also those with the highest evaluations. In turn, it should be noted that the results provided by the OWA operator are normalized in $[0,1]$, and the sum of the estimated weights equals 1. Thus, these results should be considered as the relative importance of the logistics services attributes.

It should be noted that the RR approach may discriminate better the performance of the examined quality attributes. This is somehow expected, given the non-linear nature of the applied formula.

Summarizing results conducted analysis the Servqual method and RR approach implies that is no service gap in the examined logistics service attributes, since the most important attributes are those having the highest evaluations.

In relation to publications of various authors (Kozerska 2010, Dyczkowska 2008, Brdulak 2008, Operator Logistyczny Roku 2011) as well as based on the results of surveys it should be noted that the quality of the service offered to the customer 
is still very important, as also indicated by the high ratings of the respondents (scores above 4 points where 4 indicates a high level of quality of service ).

\section{ACKNOWLEDGMENT}

The research is supported by the Polish National Centre for Research and Development (Agreement No E!6726/41NCBIR/12).

\section{REFERENCES}

[1] B.S. Ahn, and S.H. Choi, "Aggregation of ordinal data using ordered weighted averaging operator weights", Ann Oper Res, 2012, No. 201, pp. 1-16.

[2] B.S. Ahn, B.S., "Compatible weighting method with rank order centroid: Maximum entropy ordered weighted averaging approach", European Journal of Operational Research, 2011, Vol. 212, No. 3, pp. 552-559.

[3] F.H. Barron and B.E. Barret, "Decision quality using ranked attribute weights", Management Science, 1996, Vol. 42, No. 11, pp. 1515-1523.

[4] H. Brdulak, Zrównoważony rozwój w sektorze TSL w Polsce - szanse i zagrożenia, Wydawnictwo Wirtualny Leksykon Transportu i Logistyki, Warszawa 2008.

[5] H. Brdulak, "Satysfakcja klientów w branży TSL", Rzeczpospolita, 2009, No. 72.

[6] E. Briggs, T.D. Laundry, and P.J. Daugherty, "Investigating the influence of velocity performance on satisfaction with third party logistics service", Industrial Marketing Management, 2010, No. 39, pp. 640-649.

[7] F. Buttle, "SERVQUAL: review, critique, research agenda", European Journal of Marketing 1995, Vol. 30, No. 1, pp. 8-32.

[8] Z. Chaohe, "Logistics Service Quality Evaluation", Communications in Information Science and Management Engineering, 2011, Vol. 1, No. 1, pp.16-21.

[9] K. Chen, C. Chang, and C. Lai, "Service quality gaps of business customers in the shipping industry", Transportation Research Part E, 2009, No. 45, pp. 222-237.

[10] J. Dyczkowska, "Znaczenie TSL w logistyce dystrybucji - studium przypadku", Logistyka, 2011,No. 2, pp. 129-138.

[11] T. Gajewska, "Kryteria jakości usług logistycznych w transporcie chłodniczym", Doctoral thesis, University of Economics (in Polish), Cracow, 2012.

[12] T. Gajewska, M. Lisińska-Kuśnierz, "Customer satisfaction with the quality of the logistics services", LogForum, 2014, No. 10 (1), pp. 1319.

[13] S. Gounaris, "Measuring service quality in B2B services: an evaluation of the SERVQUAL scale vis-à-vis the NDSERV scale", Journal of Services Marketing, 2005, Vol. 19, No. 6, pp. 42-43.
[14] E. Grigoroudis and Y. Siskos, Customer satisfaction evaluation: Methods for measuring and implementing service quality, Springer, New York 2010.

[15] C. Ham, W. Johnson, A. Weinstein, R. Plank, and P. Johnson, "Gaining Competitive Advantages: Analyzing the Gap between Expectations and Perceptions of Service Quality", International Journal of Value-Based Management, 2003, Vol. 16, No. 2, pp. 197-203.

[16] Ch.J.Huang, and K.P. Huang, "The logistics capabilities scale for logistics service providers", Journal of Information and Optimization Sciences, 2012, Vol. 33, No. 1, pp. 135-148.

[17] G.F. Hundy, A.R. Trott, and T.C. Welch, Refrigeration and AirConditioning (Fourth Edition), Butterworth Heinemann, 2008.

[18] A.K., Jaiswal, "Customer satisfaction and service quality measurement in Indian call centres", Managing Service Quality, 2008,Vol. 18, No. 4, pp. 405-416.

[19] Ch. Jayawardhena, "The impact of service encounter quality in service evaluation: evidence from a business-to-business context", Journal of Business \& Industrial Marketing, 2010, Vol. 25, No. 5, pp. 338-348.

[20] J. Juga, J. Juntunen, and D.B.Grant, "Service quality and its relation to satisfaction and loyalty in logistics outsourcing relationships", Managing Service Quality, 2010, Vol. 20, No. 6, pp. 496-510.

[21] P. Kotler and A.R. Andreasen, "Strategic Marketing for Nonprofit Organizations ( $7^{\text {th }}$ ed.)",Upper Saddle River, NJ:Prentice-Hall 2008, pp. 605.

[22] M. Kozerska, "Pomiar poziomu zgodności percepcji operatorów logistycznych ich klientów za pomocą metody Servqual", Logistyka, 2010, No. 2, pp. 162-170.

[23] M. Liu, W. Saman, and F. Bruno, "Development of a novel refrigeration system for refrigerated trucks incorporating phase change material", Applied Energy, 2012, No. 92, pp. 336-342.

[24] A. Parasuramann, V.A. Zeithaml, and L.L. Berry, "Conceptual Model of Service Quality and its Implications for Future Research", Journal of Marketing, 1988, No. 49, pp. 41-50.

[25] Raport Specjalny 2009-2012, Badania satysfakcji klientów, Operator Logistyczny Roku.

[26] R. Roberts and P. Goodwin, "Weight approximations in multi-attribute decision models", Journal of Multi-Criteria Decision Analysis, 2003, Vol. 11, No. 6, pp. 291-303.

[27] J. Xu, "Logistics Service Quality Analysis Based on Gray Correlation Method", International Journal of Business and Management, 2008, Vol. 3, No. 1, pp. 58-61.

[28] A.T. Stoddard, TCRP Report 154 Developing, Enhancing, and Sustaining Tribal Transit Services: A Guidebook, Transportation Research Board, 2012. (tcrp_rpt_154.pdf) 